\title{
EUROPEAN GREEN DEAL AND THE NEW POLICY GOALS IN TRANSPORT AND MOBILITY - HOW GAMIFICATION CAN INFLUENCE PRO-ENVIRONMENTAL BEHAVIOUR FOR CUTTING CARBON EMISSIONS IN THE EU1
}

\author{
Miruna BUTNARU-TRONCOTĂ, PhD \\ National University of Political Science and Public Administration (SNSPA), \\ Bucharest/Romania
}

\begin{abstract}
Road traffic is one of the major sources of many of the worst pollutants, including carbon dioxide (CO2), carbon monoxide, carcinogenic particles and noise. The past decades have seen a dramatic rise in these harmful effects on human health, that proved to cause at the same time massive damage to the natural and built environment. In response to this aggravating situation, the new European Commission's President Ursula von der Leyen placed as the centrepiece of her political mandate 'the European Green Deal', a comprehensive climate and nature package of measures to make Europe climate neutral by 2050. To reach this very ambitious goal, there is a need for very creative and efficient policy solutions. And this is the scope of the current study.
\end{abstract}

1 The article is part of the development of a study on the application of the game approach in logistics and transport training (Output Title O4) under the Erasmus + strategic partnership project „Building an innovative network for sharing of best educational practices, incl. game approach, in the area of international logistics and transport", Project number: KA203 / HE-25 / 13.09.2019 
As the sustainability concerns become vital for policy planning, the paper advocates for the need of all EU's main stakeholders to realise the potential of 'green gamification' to help EU member states reach these ambitious policy goals, particularly in the field of transport and mobility - which are of crucial importance for overall CO2 reduction. Placed at the intersection of technology innovation and the need to find more efficient ways to protect the environment, 'green gamification' is an emerging concept that refers to the usage of game mechanics when it comes to engaging people, with the purpose to change their behaviour on sustainability issues. In short, it aims to motivate a sustainable behaviour within companies, institutions and citizens, with the use of interactive games, in order to fight against pollution and climate change. Applied to the field of transport and mobility, green gamification implies using strategies to cut carbon emissions especially by convincing people to reduce the use of private cars. But how can we better incentivise citizens' behaviour for cutting carbon emissions and achieve the new EU transport and mobility policy goals for 2050? To tackle this relevant question the article aims to assess the potential of 'green gamification' to help EU member states reach these ambitious policy goals.

Keywords: carbon emissions; European Union; gamification; Green Deal; pollution; transport.

\section{INTRODUCTION}

The negative effects of global warming and climate change for people and the environment are well known in the scientific world for decades. However, the topic has been on the public debate agenda for only several years. The topic is more relevant than ever, as we are currently passing through a paradoxical period with top level figures and heads of states that promote 'climate change denial' on one end, and with the United Nations declaring climate change as 'the defining issue of our time" (UN, 2020) on another. Air quality in particular has become a major area of concern for policy makers, as it influences all other policy areas because it directly impacts human health. Research showed that 
poor air quality areas are usually polluted by Nitrogen dioxide (N02), which is a highly reactive gas emitted by vehicles, power plants and industries (WHO, 2018). The gas has many harmful effects on human lungs, increasing the risk for heart and lung diseases. There are multiple actors that can join forces to reduce air pollution and recent technological innovations have offered multiple ways to tackle and solve the environmental crisis. It is acknowledged that proper solutions for enhancing air quality and fighting against pollution require concerted actions at local, national, regional and global level.

The European Union (EU) has always been in a leading position at global level when it comes to the fight against climate change and reducing $\mathrm{CO} 2$ emissions. For decades, it has set ambitious measures and goals to reduce its greenhouse gas emissions and set an example for other parts of the world. In this worrying context, the EU has established, with the European Green Deal an unprecedented ambitious goal: to achieve a 90\% reduction in emissions by 2050 . The climate change policies, regarding the improvement of air quality and tackling the climate crisis are directly affecting the EU transport sector, which currently finds itself at a crossroads. The local administrations take a lot of pressure these days, considering they are challenge to support the transformation of local communities into "smart communities" - or, in other words, into "smart cities". Conceptually, turning to smart policies, increasing the efficiency of public transport and reducing pollution play a central role. Particularly the issue of reducing personal cars traffic and enhancing use of public transport as ways of reducing pollution are policy areas under direct scrutiny by both NGOs and governments at EU level.

One of the main problems identified by the study, that definitely requires a more careful attention is the constant rise in greenhouse gas emissions from the transport sector, which threatens to jeopardise the EU's efforts to achieve its Green Deal goals. Thus, in the next 5 to 10 years it is expected that the so-called 'sustainable mobility' model will increase in importance. Other possible solutions and proposals need to be explored. The main research question that the current study aims to address is: how can the EU and member states better incentivise citizen's behaviour for cutting carbon emissions and help respecting the new EU transport and mobility policy goals for 2050? In order to assess this 
question, the current study aims to explore some tools belonging to the field of eco-innovation, which implies using technology and game mechanics to help achieving Green Deal targets and reduce pollution. The implementation of sustainable and innovative means of transport plays an important role both in the EU's energy and the EU's climate objectives. One of the main challenges of all EU policy makers is changing the population's mobility behaviour. Assuming this task, in this exploratory policy research, the purpose is to deepen current knowledge on the emerging concept of 'green gamification' aiming to provide possible policy making solutions to influence pro-environmental behaviour for cutting carbon emissions in the EU.

One possible answer that the paper attempts to offer is through the help of new technologies, or more precisely by applying the principles of 'gamification' in order to convince more citizens to renounce the use of their personal cars and instead turn to using public transport as a potential solution to the identified problem. The main hypothesis to be tested is: principles of so-called 'Green Gamification' can help the EU member states to reduce air pollution by enhancing the use of public transport in big cities. Thus, the purpose of this study is to analyse the areas in which gamification has the potential to improve transport sustainability in the context of the EU's new policy goals set by the 'Green Deal'.

The article is organised as follows: the first part will focus on describing the main policy problems in the fields of transport and combating pollution and the main documents and regulations in the EU on these topics with a focus on Green Deal objectives. Then, a short literature review will explore the concept of gamification and of 'green gamification' as used in transport contexts, and will provide the underpinning theory as to why and how gamification may be most useful for EU's strategy for cutting carbon emissions. The second part will synthesise the current practice in other countries regarding the range of interventions offered thus far in public and active transport. It will discuss the main benefits of 'green gamification' of carbon reduction based on a series of best practices and success stories applied on urban transport. The last part will explore areas where gamification could be successfully applied in the case of cutting carbon emissions in EU like shifting transport modes and reducing 
traffic congestion and will try to advocate for a possible positive impact of 'green gamification'. Lastly, the conclusions will list a series of policy recommendations and lessons learnt on ways to incentivise citizen's behaviour to achieve new EU transport and mobility policy goals for 2050.

\section{CUTTING CARBON EMISSIONS IN THE EU - BALANCING MAJOR POLICY ISSUES IN TRANSPORT AND AIR QUALITY}

This section aims at identifying the major policy concerns that the article tries to tackle. Is road traffic correlated with increasing pollution and deteriorating air quality levels? Experts agree on identifying road traffic as one of the major sources of many of the worst pollutants, including carbon dioxide (CO2), carbon monoxide, carcinogenic particles and noise (Zhanga \& Battermanb 2013). As road traffic continues to increase, so is the pollution. During the past decades we saw a dramatic rise in these harmful effects, that proved to cause massive damage to the natural and built environment and have serious effects on human health. According to the World Health Organisation (WHO), air pollution is the single largest environmental health risk in Europe (WHO 2019). The Urban NO2 Atlas (2019) provides a first indication for the relative effectiveness of mobility policies aimed at reducing urban NO2 pollution concentrations in European cities. They underline that road transport is one of the main sources of urban Nitrogen dioxide NO2 pollution. Researchers showed that traffic congestion increases vehicle emissions and degrades ambient air quality, and recent studies have shown excess morbidity and mortality for drivers, commuters and individuals living near major roadways (Zhanga \& Battermanb 2013).

Compared to all other policy areas, EU transport policy raises some of the biggest dilemmas for EU policy makers, providing many opportunities that come together with many challenges. The transport sector is a strategically important: it makes a vital contribution to the EU's overall economy and employment, being at the same time a cornerstone of European integration and vital for fulfilling the free movement of individuals, services and goods. 
Transportation is also a major contributor to the economy, representing more than $9 \%$ of EU gross value added (European Investment Bank 2020). Transport services alone accounted for around $€ 664$ billion in gross value added and they employ around 11 million people. But, in the same time, transport plays a crucial and worrying role in climate change and increasing poor air quality and pollution. EU recent data shows that urban transport represents almost a quarter (23\%) of the EU's greenhouse gas emissions (GHG) (European Environmental Agency 2019). Thus, it is considered the main cause of reduced air quality in cities, which poses a serious threat to public health. More specifically, road transport alone is responsible for almost a fifth of total EU emissions with $73 \%$ of total emissions come only from transport. This has a very negative impact on EU citizens as it was shown that air pollution is responsible for more than 430,000 premature deaths (European Commission, 2017). The ever-growing desire for greater mobility and flexibility inside the EU that brought economic growth and new opportunities came together with very high costs against the citizens' health, as growing air pollution indicators show. The European transport policy still faces many sustainability challenges. Most expert reports show that 'Transport is the only sector in the EU whose GHG emissions have risen since 1990' (European Environmental Agency 2018). Particularly the high reliance on the passenger car as a means of transport across the EU has contributed to traffic congestion in big cities and pollution in many urban areas and on many major transport arteries. However, mobility and transport keep Europe moving and the economy growing: people need to commute and travel, while businesses must be able to deliver goods and services. Without transport, the internal market would not function, nor would European industry be competitive. In this field EU decision makers need to balance between measures that promote and develop transport routes and increase mobility, but also limit its negative impact on air quality and pollution.

At the level of the EU decision making system, both fields of transport and environment are areas of shared competence, each with a dedicated Directorate General (DG) in the Commission, that oversees EU legislation application and member states compliance with EU rules. The EU exercises its competence in these domains, including on reducing the emissions resulting from transport 
activities. Furthermore, climate change and certain negative environmental impacts are a trans-boundary problem, where coordinated EU action can effectively supplement and reinforce national and local action. Let us have a brief overview over EU policy makers solutions to this problem.

Already back in 2000 the European Commission established the European Climate Change Programme (ECCP) to help identify the most environmentally and cost-effective policies and measures that can be taken at the European level to cut greenhouse gas emissions. The 'sustainable mobility' model gained even greater importance alongside the opening-up of transport markets and the creation of the Trans-European Transport Network. Two decades after, the Commission launched the European Green Deal in December 2019, when the EU leaders endorsed the objective of achieving a climate-neutral EU by 2050 . Cities started monitoring their air quality using the same standards and this allowed more comparative research and research on evolution of air pollution and their effects on human health.

While searching for better solutions, the Commission lead by Jean-Claude Juncker (2014-2019) came with a set of legislative initiatives that aimed at increasing the share of low-and zero-emission vehicles powered by alternative fuels in the EU. This was also intended to improve the quality of life of citizens, while keeping a highly competitive industry capable of generating sustainable growth. With renewed political momentum following the Paris COP21 agreement signed in 2015, road transport started to be perceived by EU policy makers as an important part in fighting climate change. EU does not only oblige industry to meet targets for cleaner transport, but are also committed to building the required alternative fuel infrastructure. In recent years EU encouraged new charging solutions and has built the legal framework to move more freight off the road. It also launched new targets on GHG reductions. Consequently, one of the 4 main themes of EU's "Road Strategy" published in 2017 is "decarbonisation", which implies focusing on encouraging clean and sustainable mobility (European Commission 2017). The EU Road strategy identified the following major challenges in EU transport systems:

- congestion: which affects both road and air traffic; 
- sustainability: transport still depends on oil for most of its energy needs, which is environmentally and economically untenable;

- air quality: by 2050 , the EU must cut transport emissions by $60 \%$ compared with 1990 levels, and continue to reduce vehicle pollution;

-infrastructure: the quality of transport infrastructure is uneven across the EU;

- competition: the EU's transport sector faces growing competition from fastdeveloping transport markets in other regions (European Commission 2018).

Predictably, directly affected by this whole phenomenon of climate change actions in the field of air quality - the EU transport sector is today at a crossroads. A lot of pressure is put on local governments and administrations, that are faced with the big challenge of transforming into 'smart cities' in which public transport and reduced pollution plays a central role. Particularly the issue of reducing personal cars traffic and enhancing use of public transport as ways of reducing pollution are policy areas under direct scrutiny by both NGOs and governments at EU level.

But all these measures discussed above were not enough. The transport sector has not seen the same gradual decline in emissions as other sectors: emissions only started to decrease in 2007 and but still remained higher than in 1990 until 2017. Within this sector, as mentioned above, road transport is by far the biggest emitter accounting for more than $70 \%$ of all GHG emissions from all means of transport. In order to reduce these alarming figures, and based on the global shift towards a low-carbon, circular economy already underway after the Paris Agreement, in 2016 the Commission published a communication entitled 'A European Strategy for Low-Emission Mobility' (COM(2016)0501), in which it proposed specific measures to accelerate the decarbonisation of European transport. This strategy aimed to ensure that Europe stays competitive and is able to respond to the increasing mobility needs of both its population and its commerce. At the same time, it aimed that Europe reaches a zero emissions standard, as established in the 2011 White Paper on the future of transport (European Commission 2011), focusing on adequately contributing to achieving the COP 21 Paris Agreement goals. Overall, the Juncker Commission's target 
was the reduction of the GHG by at least $40 \%$ until 2030, compared to 1990 levels (European Commission 2017).

Another result of the intense preoccupation with air quality and reducing levels of pollution was the Directive 2016/2284, also called the National Emission Ceilings (NEC) Directive, currently the most important piece of EU regulation supporting the achievement air quality levels that do not generate significant negative effects or risks to human health and the environment. Under its previsions, Member States are obliged to draw up, adopt and implement programs in order to limit their annual emissions. This obviously impacts primarily the field of road transport. Member States were required to fully transpose this EU Directive into national law by 1 July 2018. This is the main legislative instrument to achieve the 2030 objectives of the Clean Air Programme and it sets national emission reduction commitments for each EU Member State for the period 2020 to 2029 and more ambitious ones as of 2030.

Most recently, on 26 June 2020, the Commission adopted its report to the European Parliament and the Council on the progress made on the implementation of Directive (EU) 2016/2284 on the reduction of national emissions of certain atmospheric pollutants. The European Commission now estimates that the majority of member states are off-target to deliver on their air pollution reduction commitments for 2020 and 2030. Also, latest European Environment Agency report on 2020 presented the most recent air pollutant emissions inventory data for the period 2010-2018, as reported by the Member States in February 2020. It shows some really encouraging progress - that Member States are in compliance with their commitments and that the collective efforts of the Member States have resulted in the total EU emissions of the four main pollutants (NOx, NMVOC, NH3 and SO2) being well below their respective ceilings for every year since 2012. Nevertheless, it also shows that progress done so far is insufficient to reach the more ambitious emission reduction commitments set for the period 2020-2029 and even more so for 2030 onwards (European Environment Agency, 2020). Moreover, it draws attention to the fact the COVID pandemic might have a positive effect on fulfilling these targets as "reductions in economic activity across Europe in 2020 associated with the COVID-19 lockdowns is expected to lower emissions and may boost 
progress towards meeting reduction commitments" (European Environment Agency 2020).

Table no 1. Emission reduction efforts in EU member states for 2020 and 2030.

\begin{tabular}{|c|c|c|c|c|c|c|c|c|c|c|}
\hline \multirow[b]{2}{*}{ Country Name } & \multicolumn{5}{|c|}{2020} & \multicolumn{5}{|c|}{2030} \\
\hline & NH3 & NMVOC & NOx & PM2.5 & $\mathrm{SO} 2$ & NH3 & NMVOC & NOx & PM2.5 & $\mathrm{SO} 2$ \\
\hline Austria & - & $\checkmark$ & $\checkmark$ & $\checkmark$ & $\checkmark$ & - & $\checkmark$ & - & - & $\checkmark$ \\
\hline Belgium & $\checkmark$ & $\checkmark$ & $\checkmark$ & $\checkmark$ & $\checkmark$ & - & $\checkmark$ & - & - & $\checkmark$ \\
\hline Bulgaria & $\checkmark$ & - & $\checkmark$ & - & $\checkmark$ & 0 & - & - & - & $\checkmark$ \\
\hline Croatia & $\checkmark$ & $\checkmark$ & $\checkmark$ & $\checkmark$ & $\checkmark$ & 0 & - & - & - & 0 \\
\hline Cyprus & - & - & - & - & - & - & - & - & - & - \\
\hline Czechia & $\checkmark$ & - & $\checkmark$ & - & $\checkmark$ & - & - & - & - & - \\
\hline Denmark & - & $\checkmark$ & - & - & $\checkmark$ & - & $\checkmark$ & - & - & - \\
\hline Estonia & $\checkmark$ & $\checkmark$ & $\checkmark$ & $\checkmark$ & $\checkmark$ & $\checkmark$ & $\checkmark$ & - & $\checkmark$ & - \\
\hline Finland & - & $\checkmark$ & $\checkmark$ & - & $\checkmark$ & - & - & • & - & $\checkmark$ \\
\hline France & - & $\checkmark$ & - & $\checkmark$ & $\checkmark$ & - & - & - & - & - \\
\hline Germany & - & $\checkmark$ & - & $\checkmark$ & $\checkmark$ & - & $\checkmark$ & - & - & - \\
\hline Greece & $\checkmark$ & $\checkmark$ & $\checkmark$ & $\checkmark$ & $\checkmark$ & $\checkmark$ & - & ○ & - & $\checkmark$ \\
\hline Hungary & - & $\checkmark$ & $\checkmark$ & - & $\checkmark$ & - & - & - & - & - \\
\hline Ireland & - & - & ○ & $\checkmark$ & $\checkmark$ & - & - & - & - & - \\
\hline Italy & $\checkmark$ & $\checkmark$ & $\checkmark$ & $\checkmark$ & $\checkmark$ & - & - & - & - & $\checkmark$ \\
\hline Latvia & - & $\checkmark$ & - & $\checkmark$ & $\checkmark$ & - & - & ○ & - & $\checkmark$ \\
\hline Lithuania & - & - & - & $\checkmark$ & - & - & - & - & $\checkmark$ & - \\
\hline Luxembourg & $\checkmark$ & $\checkmark$ & $\checkmark$ & $\checkmark$ & $\checkmark$ & - & $\checkmark$ & - & $\checkmark$ & $\checkmark$ \\
\hline Malta & $\checkmark$ & - & - & $\checkmark$ & $\checkmark$ & $\checkmark$ & - & - & $\checkmark$ & $\checkmark$ \\
\hline Netherlands & $\checkmark$ & $\checkmark$ & $\checkmark$ & $\checkmark$ & $\checkmark$ & - & $\checkmark$ & - & $\checkmark$ & $\checkmark$ \\
\hline Poland & $\checkmark$ & - & - & - & - & - & - & - & - & - \\
\hline Portugal & $\checkmark$ & $\checkmark$ & $\checkmark$ & $\checkmark$ & $\checkmark$ & - & - & - & - & - \\
\hline Romania & $\checkmark$ & $\checkmark$ & - & - & $\checkmark$ & - & - & - & - & - \\
\hline Slovakia & $\checkmark$ & $\checkmark$ & $\checkmark$ & $\checkmark$ & $\checkmark$ & - & $\checkmark$ & - & $\checkmark$ & - \\
\hline Slovenia & $\checkmark$ & $\checkmark$ & $\checkmark$ & - & $\checkmark$ & 0 & - & - & - & - \\
\hline Spain & - & $\checkmark$ & $\checkmark$ & - & $\checkmark$ & - & - & - & - & - \\
\hline Sweden & 0 & $\checkmark$ & - & $\checkmark$ & $\checkmark$ & - & $\checkmark$ & ○ & $\checkmark$ & $\checkmark$ \\
\hline United Kingdom & - & $\checkmark$ & - & - & $\checkmark$ & - & - & - & - & - \\
\hline
\end{tabular}

Current emission levels below the emission reduction commitment

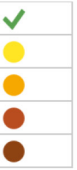

Emission reduction needed by less than $10 \%$ from current levels

Emission reduction needed by $10 \%$ to $30 \%$ from current levels

Emission reduction needed by $30 \%$ to $50 \%$ from current levels

Emission reduction needed by more than 50 \% from current levels

Source: European Environment Agency, 2020.

https:/ / www.eea.europa.eu/themes/air/air-pollution-sources-1/nationalemission-ceilings/national-emission-reduction-commitments-directive 
It is also worth mentioning another relevant policy document issued in March 2019, close to the end of the Juncker Commission's mandate. EC promoted the next generation of $\mathrm{CO} 2$ emissions reduction standards for transport in its most recent report titled 'Transport in the European Union - current trends and issues', produced by the Directorate-General for Mobility and Transport (DG MOVE) (European Commission 2019). EC's estimates suggest that passenger transport will only increase by $42 \%$ by 2050 , and freight transport by $60 \%$. This puts pressure on the transport network as well as the environment - so innovative solutions need to be found at all levels of EU governance.

\section{ON THE ROAD TO A CLIMATE-NEUTRAL EUROPE BY 2050 - THE EUROPEAN GREEN DEAL AND THE NEW TARGETS FOR REDUCING POLLUTION}

This section shall offer a short overview of the most recent EU solutions to combat climate change - the much-talked-about European Green Deal and its targets, with a focus on the inter-connected fields of transport and reducing air pollution.

In response to the current aggravating situation in rising carbon emissions in the EU, the new European Commission's President elect - Ursula von der Leyen placed as the centrepiece of her political mandate 'the European Green Deal', a comprehensive climate and nature package of measures to make Europe climate neutral by 2050. In December 2019, when it launched its political priorities, President vor der Leyen announced that one of the priorities of the new EC will be the fight against climate change and environmental degradation considered as 'existential threats' to Europe and the world (European Commission 2019). To that end, Frans Timmermans, designated Executive Vice-President-designate for the European Green Deal, announced that the Deal lays down the actions meant to turn Europe into the first carbon-neutral continent by 2050 compared to 1990 levels. Moreover, the Green Deal proposes an ambitious rethinking of the European economy, transport, building and energy sectors. It has a total of 8 
policy areas but this study will focus on the inter-connection between only 2 main policy areas: 'Sustainable mobility' that aims to promote more sustainable means of transport and "Eliminating pollution" that comprises measures to cut pollution rapidly and efficiently. The plans of the current Von der Leyen Commission are more ambitious that Juncker's Commission, hoping to increase the levels up to 50-55\% until 2030 - with $15 \%$ higher than the previous targets. In line with President Von der Leyen's Political Guidelines, EU's future policy actions will be guided by the ambition of the Deal to ensure that transport makes its important contribution to climate neutrality by 2050. The new strategy will thus include ambitious measures aimed at significantly reducing $\mathrm{CO} 2$ and pollutant emissions across all modes. In this context, the effective implementation of the NEC Directive will be key to reaching the zero-pollution goal of the new European Green Deal. Effective implementation of clean air legislation forms an essential contribution to 'a zero-pollution ambition for a toxic-free environment' announced by the Commission and related initiatives, planned for 2021.

Europe's answer to the emission reduction challenge in the transport sector is an irreversible shift to low-emission mobility. By midcentury, GHG from transport will need to be at least $60 \%$ lower than in1990 and be firmly on the path towards zero. President-elect von der Leyen committed to a cross-cutting zero-pollution strategy that will: "protect citizens' health from environmental degradation and pollution, address air and water quality, hazardous chemicals, industrial emissions, pesticides and endocrine disruptors". To do this, it will carry out a series of initiatives that will protect the environment and boost the green economy. This transition process of the European Union (EU) economy to a more sustainable future must occur gradually. Specific actions should be taken by all sectors, particularly energy, transport, agriculture, as well as by industries. The EU will also provide financial support and technical assistance to help people, businesses and regions that are most affected by the move towards the green economy. This is called the 'Just Transition Mechanism' and will help mobilise at least $€ 100$ billion over the period 2021-2027 in the most affected regions (European Commission 2019). 
The situation of air pollution in the EU has improved over the last years, but it is still worrying. According to recent published by the European Environment Agency (2019) average carbon dioxide (CO2) emissions from new passenger cars registered in the EU, Iceland, Norway and the United Kingdom (UK), increased in 2019, for the third consecutive year. Meanwhile, CO2 emissions from new cars and vans registered in the bloc increased again in 2019 for the third consecutive year. As such, air pollution continues to be one of the major challenges in Europe. In order to reach the sustainability objectives of the European Green Deal action at EU level it is necessary to ensure efficient and strong initiatives that can deliver the needed climate and environmental impacts.

After describing the main policy solutions EU offered to these challenges in the field of road traffic and environmental protection we need to explore possible solutions that could help member states achieve the very high standards and goals set by the European Green Deal. The current study intends to propose the uses of a specific branch of tech innovation, namely eco-innovation1, as a potential useful tool for decarbonisation. Technology innovation proved in the last decade to be a great resource for achieving these ambitious goals in the EU. Moreover, eco-innovation is a new concept of great importance to business and policy makers, covering mainly innovations of environmental benefit. Our main aim in this study is to explore its uses for reducing pollution in EU cities. This solution involves all economical, political, scientific actors dealing with environmental technologies at global, European and national levels and implies multiple funding programmes from the European Commission that support ecoinnovation. Multi-stakeholder participation is required for all these challenges to be addressed. Before exploring the proposed solution to reducing road transport through green gamification, with the purpose of creating real positive social and

1Eco-innovation is any innovation resulting in significant progress towards the goal of sustainable development, by reducing the impacts of our production modes on the environment, enhancing nature's resilience to environmental pressures, or achieving a more efficient and responsible use of natural resources. See more in https://ec.europa.eu/environment/ecoap/frontpage_en 
environmental impact, let us first clear the main concepts and explore a bit the state of the art in the boosting field of gamification.

\section{STATE OF THE ART ON ‘GAMIFICATION’ - A NEW-OLD CONCEPT UNDER SCRUTINY}

Before focusing on the more specific form of 'green gamification' applied to the policy field of EU transport and mobility that we will employ in this study, let us first have a brief overview of gamification in general and the disputes around it in the literature. The concept of 'gamification' is not new, but in recent years it started to be more frequently used in various forms outside the fields of digital media and new technologies, drawing attention of scholars and practitioners alike. A diverse range of fields, from marketing to pedagogy or human resources discuss and use gamification as a possible solution to their specific efficiency and sustainability problems. Consequently, it is no surprise that one can find an array of definitions and descriptions of what became in the last decade a 'trendy' and omnipresent concept. With this came also a lot of confusion over what the term really means. And this is more worrying as the concept gained more and more popularity. Already in 2012 'gamification' was first listed as one of the top sustainable business trends (Makower 2012, 9). Gamification, also known as 'gameful design' was mostly used in fields such as training, education, health, well-being, business and HR and, as we will discuss in more detail, also in public policy, transport and for promoting eco-friendly behaviours.

Intuitively, 'gamification' as a term originated in the digital media industry. For the first time the term was gaining interest in the academic world and the Gamification Research Network was established after a workshop was run at the 2011 Computer-Human Interaction (CHI) conference (Fit-Walter nd). Even though it was used in various other contexts before, without a clear / shared understanding, the term benefited of a clear definition and widespread adoption only after 2010 with Deterding et al's (2011) definition being one of the most 
widely cited in gamification research: "The use of game design elements in nongame contexts". Similarly, Zicherman and Cunningham (2011) offer a fairly broad definition of gamification as "game-thinking and game mechanics to engage users and solve problems" (p. XIV) adding on the utilitarian aspect of the process. In a more customer/ beneficiary centered way of understanding, Huotari and Hamari (2012) defined gamification as "a process of enhancing a service with affordances for gameful experiences to support user's overall value creation." Additionally, Dominguez et al. (2013) proposed also a more detailed definition: "Incorporating game elements into non-gaming software applications to increase user experience and engagement". Later on, Werbach (2014) defined gamification as "the process of making various activities more game-like" focusing on the crucial space between the components that make up games and the holistic experience of gamefulness. The latest definition by Landers et al. (2018) states that gamification is "using game-like elements to make non-game tasks more interesting". They also make a distinction that incorporates also the criticisms that were expressed against the broadness of the concept during the years. The distinction is between what they call "legitimate gamification" that has, in their opinion, a transformative potential, but only when used skilfully and "rhetorical gamification" defined as "at best novice gameful design and at worst a swindle, an attempt to make something appear 'game-like' purely to sell more gamification" Landers et al. $(2018,45)$. As seen, gamification research uses key concepts from related areas which include - game design, behavioral economics, community management and loyalty programs to influence behavior.

What most definitions of the term have in common is that they refer to it as a process of adding 'game-like elements' to some real-world elements with various purposes. Some of its most often mentioned characteristics are that it consists of high-choice, low-risk engagements in a clearly structured environment that is very enjoyable for the user. Moreover, most definitions point to the fact that applying gamification on certain products or services encourages competition between consumers that are focused on reaching some objectives, milestones or a quantifiable outcome that they could get pride in. But why did gamification suddenly become so popular? The process it refers to 
existed even before it was named gamification and discussed in the specialised literature or explicitly mentioned in the business industry, under different names and forms. For example, its principles were already present in loyalty marketing programs in Hypermarkets, Hotels, Clubs or Frequent Flyers programs of air companies that offered bonuses to their members. But smartphones, big data and the internet were the main game-changers. Only with these technological innovations, and through computing-including the Internet, fast computation, and cheap, pervasive devices like smart phonesthat "gamification has become a viable strategy for influencing everyday behaviors" (Froehlich 2015, 3). In their search for creating new ways to ensure longer-term engagement, extending relationships, and enhancing customer and employee loyalty, companies focused on various ways of introducing 'gamification' in their products. Their motivation was the proven positive effect of gamification - the fact that game techniques were used to make activities more engaging and fun and customer levels of satisfaction grew visibly. Over the years more and more companies in very different fields realised, based on the high rate of success and popularity that apps using gamification had, that it became a very strong motivational and persuasive strategy mediated by technology and design to change consumer behaviour and increase sales and brand perception.

Therefore, considering the current context the question is: how did gamification became such a disputed term, despite its popularity and efficiency? While gaming became an industry with huge growth potential, gamification became in itself a growing market on its own, particularly after some Tech giants like Amazon used it. The attention to this process was initially only business-driven, based on consumer marketing analyses that showed that accumulating rewards or status symbols motivates continued engagement and increases sales, keeping customers loyal to brands. In this sense, it is worth underlining that one thing that all approaches to gamification share is the focus on giving feedback to users/players to let them know how they are doing, and follow progress in time, which proved to be a motivating factor that shapes future interactions of the user with the 'gamified' product connecting it with rewarding processes like validation, feeling of achievement and self-fulfilment. As such, it turned out that 
gamification shortly became a powerful strategy for engaging, influencing and motivating diverse groups of people in taking action, following a profit driven agenda that made the entire process more fun, easier and more efficient. But these traits became also the main challenges and raised criticisms especially when investigations on the vulnerability to data manipulation became public and systematic breaches of privacy policy. Table 1 presents some examples of very successful 'gamified apps' using primarily reward and competition-based elements, such as points and badges:

Table no 2. Examples of popular apps and products using gamification. Edited by the author.

\begin{tabular}{|l|l|l|}
\hline Name of product & \multicolumn{1}{|c|}{ Use of gamification } & \multicolumn{1}{|c|}{ Field } \\
\hline Foursquare & $\begin{array}{l}\text { A location based social network that allows } \\
\text { customers to "check-in" at various venues. Its } \\
\text { gamified check-ins let users get points for } \\
\text { certain activities (such as checking into a new } \\
\text { place), get badges for checking in and even get } \\
\text { 'Mayor' status, if a user checked into a certain } \\
\text { venue on more days than anyone else in the } \\
\text { past } 60 \text { days, enabling users to compete for top } \\
\text { place while enjoying meals, shopping, movies, } \\
\text { etc. }\end{array}$ & $\begin{array}{l}\text { A smart phone application for running and } \\
\text { fitness that motivates users to exercise. It } \\
\text { allows you to add different exercise activities } \\
\text { like running, skiing or swimming (to name a } \\
\text { few) and input your routes on a map that can } \\
\text { be used to calculate your progress, shared with } \\
\text { friends, or planned in advanced and accessed } \\
\text { on your mobile phone. }\end{array}$ \\
\hline
\end{tabular}




\begin{tabular}{|c|c|c|}
\hline Name of product & Use of gamification & Field \\
\hline Kahoot & $\begin{array}{l}\text { A game-based platform for teachers and } \\
\text { students focused on motivating people in the } \\
\text { classroom. It was created to make learning both } \\
\text { easy and fun - a program that anyone can } \\
\text { easily access through any internet-connected } \\
\text { device. The Game Master - the teacher - can } \\
\text { sign up and create a game for the players to } \\
\text { participate in. The game's format is usually a } \\
\text { series of questions asked by the teacher, } \\
\text { wherein the students respond individually or } \\
\text { by team from a selection of answers. }\end{array}$ & education \\
\hline Duolingo & $\begin{array}{l}\text { A game-like language learning platform that } \\
\text { applied gamification to increase motivation } \\
\text { and engagement. The home page focuses you } \\
\text { on your progress by indicating your progress } \\
\text { and strength on each skill and showing the full } \\
\text { tree of skills in your language course. }\end{array}$ & education \\
\hline Reddit & $\begin{array}{l}\text { What started as a blog and became a huge } \\
\text { discussions forum and social network } \\
\text { particularly because of its own } \\
\text { upvote/downvote system, along with the so- } \\
\text { called 'Karma' score. The scoreboard of } \\
\text { Redditbecame the best-known example of } \\
\text { gamification created to encourage knowledge } \\
\text { sharing and collaboration on a public forum. } \\
\text { Reddit's Karma points are rewarded by the } \\
\text { community for posting popular content. You } \\
\text { gain points when your comments and links } \\
\text { that you share are upvoted, and it's taken away } \\
\text { when your links and comments are } \\
\text { downvoted. }\end{array}$ & $\begin{array}{l}\text { online forum/ } \\
\text { social network }\end{array}$ \\
\hline
\end{tabular}




\begin{tabular}{|l|l|l|}
\hline Name of product & \multicolumn{1}{|c|}{ Use of gamification } & Field \\
\hline Starbucks & $\begin{array}{l}\text { The largest coffee store chain in the world } \\
\text { launched a fun tool to get people to visit their } \\
\text { stores and buy more products. Starbucks } \\
\text { rewards their users with virtual points and } \\
\text { badges for visiting their retail outlets. When } \\
\text { they complete quests, for example "visit five } \\
\text { different Starbucks," they are rewarded with } \\
\text { points. }\end{array}$ & coffee \\
\hline
\end{tabular}

Next, discussions on the topic entered into more depth and lead to a different question: what is the real impact of gamified apps on human behaviour? By weaving suitably fun features such as leaderboards and badges into an existing system, designers tap users' intrinsic motivations so they enjoy using it more and more. In some cases this logic of inducing action and perpetuated usage can become an 'addiction' and so the uses of gamification can become very problematic.1 Another main characteristic of gamification was criticised as a negative impact on users - the fact it focuses on challenging competition between users for accumulation of points - receiving rewards achievement badges and progress at different levels ranking based on achievements and this my exaggerate competitive features particularly younger generations.

At the same time, the critiques of the concept came from its vagueness. Burke (2014) argues that gamification has gained popular attention because it is framed in a way that simplifies the difficulty of the process. Hung (2017) showed for

1 Already in 2018 the World Health Organization (WHO) introduced 'gaming disorder' in the 11th Revision of the International Classification of Diseases (ICD-11) as a pattern of gaming behavior ("digital-gaming" or "video-gaming") characterized by impaired control over gaming, increasing priority given to gaming over other activities to the extent that gaming takes precedence over other interests and daily activities, and continuation or escalation of gaming despite the occurrence of negative consequences. https://www.who.int/westernpacific/news/q-a-detail/gaming-disorder 
example that a certain product can be gamified to varying degrees, making it hard to isolate what aspect of this approach is more influential. It this sense, it was underlined that gamification can be used as simply an additional layer or it can be deeply integrated into every part of the product, so many of its definitions are too broad. We can observe that in fact the first wave of definitions and legitimation of gamification comes from early times (like 2010 onwards) when it was still considered acceptable for game designers to get users addicted to apps and use their personal data for influencing their behaviours. Most visibly after the Cambridge Analytica scandal 1 more critical points were raised against the unethical uses of digital tools in this field, using and abusing game mechanics that naturally tap intrinsic and extrinsic motivations, and changing something that already exists by integrating game design elements and principles that lure consumers into using it more. Many scholars and digital media experts accused companies that only try to maximize the time spent in consumer apps without looking at consequences (Filimon-Lecka 2020). Only recently did the literature started to discuss at length how certain products transformed the lives of their users through the gamification approach in more nuanced terms, focusing also on its shortcomings. Thus, in the last years the concept started to hold negative connotations being associated with marketing tactics and manipulative strategies for inducing addictive consumer behaviour. The process of using game thinking and game mechanics to solve problems and engage users started to be analysed also by looking at its downsides. Debates started to show that gamification is not just about points and badges, that might influence people's decisions on their game-related strategies to improve their performance, but also the same components could manipulate user's private data and mislead users into addictive behaviours or negative decisions. As a result, many scholars argue for an alternative terminology to distance academic

1 In 2018 the British company Cambridge Analytica has faced a backlash after it was proved that it used Facebook to create psychological profiles of voters in Brexit referendum and US elections back in 2016. More in https://www.nytimes.com/2018/04/04/us/politics/cambridge-analytica-scandalfallout.html 
uses of gamification from controversial or exploitative examples (Hung 2017). It was also observed that gamification became, in time, a controversial concept for different reasons: either appearing 'exploitative', or seeming 'over-simplified' and having the tendency to rely excessively on extrinsic motivation (Hung 2017). After the details that the Cambridge Analytica case revealed, both companies and governments became more reluctant to the idea that gamification implies taking the user, customer, fan and employee data, and turn it into 'actionable behavior' that supports business goals or even in some cases shady/ un-transparent political messages to be used for electoral purposes.

In short, in just a few years, gamification became a trend-setter based on the simple marketing observation that anything could be turned into a fun activity by making it seem like a game with the help of proper technology and design. Interestingly enough, gamification has gained significant attention in areas that most commonly are not set up to function like a game, but have taken inspiration from video games. By mobilising virtual rewards and playful elements like mobile apps, websites, social initiatives and even urban policies are getting more and more gamified. As was the case with all new technologies, gamification, too, started to be used not only for pleasure or profit, but also for other less ethical purposes. As such I will conclude at this point that gamification has some pros and cons regarding both its definition, and the limits of its application and even if it was explicitly mentioned only in the last decade it is still connected to older practices focused on consumer engagement. Most visibly in the post-Cambridge Analytica period (after 2018), more awareness was raised on the problematic elements of gamification, such as the fact that some apps may produce a sort of 'gamified obedience' similar to the system used by the Chinese Government or for social scoring and personal data surveillance1. This 'turn' in the field made the discussions focus more on

1 Recent research showed that in China local governments have their own social record systems that work differently, while unofficial private versions are operated at companies such Ant Financial's Zhima Credit, better known as Sesame Credit. Ant Financial is the payment firm spun out of Alibaba. It uses data from Alibaba's services to compile its score. Customers receive a score based on a variety of factors based on social 
'meaningful gamification' then on 'effective gamification' as in the past and currently more attention is given to ethical aspects of engagement design and their effects on individual users and communities alike. One can argue that these game-like techniques form a tool kit and, like any set of tools, their creators cannot regulate or anticipate how they are used, which makes the concept still very relevant, intriguing and open for re-evaluation and in-depth research.

\section{UNDERSTANDING 'GREEN GAMIFICATION' - MOTIVATING SUSTAINABLE BEHAVIOUR THROUGH GAMES}

This part explores the concept of 'green gamification' as used in transport contexts, and will provide the underpinning arguments as to why and how gamification may be most useful for EU's Green Deal strategy and EU member states application for cutting carbon emissions. As mentioned previously, gamification is a persuasive approach (aiming to provoke specific behavior on voluntary basis) so in the context of exploring solutions to problems of climate change gamification employs a type of 'green persuasiveness' towards a behaviour that is eco-friendly. Like in many other fields, game mechanics are increasingly used by companies to provide "rewards for making good, green choices" (Makower 2012; 9). In their State of Green Business report (2012), the GreenBiz Group listed green gamification as one of the top sustainable business trends. As a specific sub-type of research on gamification, it emerged in recent years at the intersection of human behavior and technology, often with respect to environmental sustainability. Basically, it involves employing motivational

media interactions and purchases carried out on Alibaba Group websites or paid for using its affiliate Ant Financial's Alipay mobile wallet. The rewards of having a high score include easier access to loans from Ant Financial and having a more trustworthy profile on e-commerce sites within the Alibaba Group. More on https://www.wired.co.uk/article/china-social-credit-system-explained 
techniques in several of the most environmentally significant domains: home resource consumption, personal transportation and waste disposal behaviors (e.g., littering and recycling). As the name suggests - green gamification refers to the use of game mechanics to engage people and change behaviour (as gamification in general) but applied on sustainability issues. It thus promoted not just any behavioural change but an explicit 'green' behavioural change that aims to reach large collectivities and not just individuals. The rise of gamification as a mechanism to encourage pro-environmental behavior emerges at the intersection of behavior-based movements in environmental psychology and persuasive technology. A proper definition of the term is: "gamification that is used as a set of motivational techniques to inspire and provoke proenvironmental interest and action" (Froehlich, 2015). It has proved efficient mostly by using sensed information to visualize and reward particular behaviors (e.g., energy-efficient consumption in the home or using sustainable transport in the city like public transportation or bicycles). But what is different when compared to marketing-oriented type of gamification that we discussion above is that for 'green gamification' the focus is put more on collaborative forms of engagement, not just on pure competition and individual material or symbolic rewards.

As discussed by specialists, and placed at the intersection of technology innovation and the need to find more efficient ways to protect the environment in the current crisis of 'climate emergency' (UNEP 2020), when applied to the particular field of EU transport and mobility policies 'green gamification' refers to the use of game mechanics to engage people and change behaviour applied on sustainability issues by reducing CO2 emissions (Lounis et al 2013). In short, it aims to motivate a sustainable behaviour within companies, institutions and citizens, with the use of interactive games, in order to fight against pollution and climate change (more in Lounis et al 2013). Applied to the field of transport and mobility, green gamification implies using strategies to cut carbon emissions especially by convincing people to reduce the use of private cars (MazurStommen \& Farley 2016). Such technologies represent the next big leap in fomenting behavior change around sustainability but in order to achieve its goals customers need to be willing to engage with private companies and causes 
through their mobile phones and devices. Literature on gamification and sustainability reveals an effective intervention on how to nudge people towards more sustainable behavior (Wolf 2020).

In their quest for using technology innovation to find more efficient ways to protect the environment green gamification has become a driver for sustainable behaviour change of interest for all stakeholders - businesses to respect new regulations, governments and international organisations like the EU to make better strategies and achieve ambitious goals, civil society organisations to find better solutions to local problems. As such, in recent years, there were more and more coordinated attempts to include green gamification in eco-friendly transport policies, particularly on the very challenging topic of reducing $\mathrm{CO} 2$ emissions. The secret ingredients that make people love games is that they are fun, gratifying, and pleasurable and green gamification tries to transfer these characteristics also to eco-friendly everyday activities that imply some effort like bike sharing. People enjoy interactivity and satisfying their curiosity. That is why green gamification works because it is both fun and connected to persuasion - a form of convincing people to do things that are in their benefit but in a fun, game like way. Green gamification can be used as a potential solution (still to be tested and its impact observed) to the very serious problem of air pollution. These persuasive methods are credited with taking thousands of cars off the road and for reducing $\mathrm{CO} 2$ emissions try changing consumer activities for personal transportation.

There is a significant amount of empirical data showing innovative ways in which technologies can help individuals monitor and reduce their carbon footprints. They show that feedback visualization successfully stimulates awareness about a user's transportation activities (McKenzie-Mohr 2011). Research shows that gamification increases consumer engagement. Bui \& Veit (2015) present statistics on how a gamified information system can change customers' behaviour towards an improved level of personal environmental sustainability. Their pioneering research was applied on a car-sharing service, showing how the application of gamification during car rides can lead to the decrease of $\mathrm{CO} 2$ emission caused by the driving behaviour of individual drivers. On a similar note, Wolf (2020) also argued, based on empirical data that 
providing eco-information in the form of a game with visual or numerical feedback enhances pro-environmental behavior.

In recent years this field saw a visible boost, so green gamification began to touch upon nearly all aspects of our everyday life from cars that rank and reward fuel-efficient driving performance (e.g., the Nissan Leaf) to sanitation services that monitor and reward home recycling behavior (e.g., Recyclebank, EcoIsland) (Froehlich 2015). Applied to the field of transport and mobility, green gamification implies using strategies to cut carbon emissions especially by convincing people to reduce the use of private cars. This strategy developed as a way to incentivise people to be more aware of their environment and change their unsustainable habits such as driving personal cars instead of public transportation. For example, applied to the field of transport and mobility, green gamification implies that citizens are encouraged to use more sustainable modes of transport through personalised positive incentives made available via a smartphone app. But the crucial question that was raised is: is gamification per se an eco-savior? Indeed, positive examples proved that it is largely focused on changing individual behaviors (e.g., eco-driving, energy use in the home), but there is doubt over whether this focus will lead to broad societal change. In a more critical approach Froehlich (2015) pinpointed the fact that any proper discussion of technology designed to inform or influence environmental behavior must also include a discussion of ethics.

Seen from a different perspective, one may also argue that an extra-challenge is that green gamification is more demanding than simple gamification because it requires not just extrinsic motivation - by adding a layer of externally driven incentives and rewards (e.g., leaderboards, points, virtual trophies) in order to create more engagement, but also a whole lot of intrinsic motivation and climate change awareness and public responsibility. There is a need to shortly mention the main downsides and limitations of this method to stir an eco-friendly behaviour. The main shortcoming to using these kinds of gamification-based solutions is that the user's behavior is shared (and monetised) with one or more third parties, including their travel and purchasing habits. Also, the huge challenge of green gamification is how to keep consumers engaged on long term. Numerous difficulties have been reported to create an incentive structure 
to encourage particular behaviors on longer periods of time. It is well known that in the field of ecology citizens need to take part in pro-environmental actions long enough until they become 'routine' and it also require a deal of personal will and effort. Froehlich rightfully highlights that "most people lack understanding about how their everyday behaviors such as showering and commuting to work affect the environment and that technology may bridge this "environmental literacy gap" by automatically sensing these activities and feeding related information back through computerized means (e.g., mobile phones, ambient displays or online visualizations)" $(2015,6)$. It is important at this point to state that before understanding how gamification can help in reducing air pollution we should start by understanding why people engage in environmentally responsible behavior in the first place. Green gamification depends a lot of citizen's own willingness to invest effort into sustainable behaviours. Another very serious challenge discussed by experts is that people are diverse and situated in diverse contexts, and so it is unlikely that one set of motivational techniques and gamification strategies will appeal to everyone. The limited ways in which green gamification can adapt to very different contexts of diverse social groups represent a big obstacle to be taken into consideration.

Next, let us shortly present a few reasons why and what forms of green gamification can prove efficient for fulfilling EU decarbonisation goals for 2050.

\section{GAMIFYING DECARBONISATION - PRINCIPLES OF GREEN GAMIFICATION APPLIED TO TRANSPORT AND MOBILITY}

This section will discuss the main benefits of 'green gamification' of carbon reduction based on a series of best practices and success stories applied on urban transport in the EU, but also outside EU. It synthesises several current practices regarding the range of interventions offered thus far to reduce the 
usage of passenger cars and increase use of public transport. This proposal comes in direct correlation with the statement made on 3rd February 2020 by the new Commissioner of Transport Adina Vălean when she presented the new "EU Strategy for Mobility and Transport in direct connection with EU's goals for the Green Deal, where she underlined the fact that "emissions of air pollutants from transport that harm our health need to be drastically reduced without delay" while also mentioning its aim of "harnessing digital technologies to make mobility smart as well as sustainable" (Vălean 2020). In the European Green Deal Communication statement, the Commission affirmed its intention to tackle all transport emission sources and explains that achieving sustainable transport means focusing on users and providing them with more affordable, accessible, healthier and cleaner alternatives to their current mobility habits. in this context, as the sustainability concerns become vital for policy planning, the paper advocates for the need of all EU's main stakeholders to realise the potential of 'green gamification' to help EU member states reach these ambitious policy goals, particularly in the field of transport and mobility - which are of crucial importance for overall $\mathrm{CO} 2$ reduction. another strong reason for using green gamification to achieve 2050 decarbonisation is that $35 \%$ of the European regional development fund will be allocated for innovations, research, smart solutions, smart cities and digitization. There are multiple financial opportunities for these types of solutions to be used by accessing EU funding. Increased use of green gamification approaches to promote the use of alternative modes of transport to passenger cars will result in improvements in air quality, reductions in noise levels, lower congestion levels and improved road safety. $\mathrm{EU}^{\prime} \mathrm{s}$ approach is that by supporting the expansion of applied gaming and gamification will not only create new solutions and methodologies to address societal issues, but it will also help SMEs to seize new business opportunities. This is in line with the new Von der Leyen Commission's priorities of Jobs and Growth, the Digital Single Market and Energy Union (European Commission 2019).

While trying to help policymakers to design carbon reduction actions, experts showed that targeted actions to reduce pollution from road traffic can include measures such as: restricting the access of certain types of vehicles to inner city 
areas, promoting alternative means of transport or applying environmental charges to the largest polluters (Urban NO2 Atlas 2019). This set of policy recommendations proposed in the paper will focus on incorporating game elements into existing systems in a way that increases user engagement in the process. Their aim would be to engage sustainable behaviours in users by introducing gamification into already existing systems of online maps and recommended trips, city administrations should apply gameplay and the structure of rules and goals to mundane tasks like choosing green transportation to go to work. This implies using some aspects of games (e.g., competition, progress tracking, rewards) with the main goal to stimulate reflection and awareness about 'green' transit to cut gas emissions and to sustain engagement. "Gamifying" green transportation decisions is based on using game-like mechanics to motivate citizens to take alternative decisions to daily using passenger cars to go to work. City administrations and local authorities will play a crucial role in delivering this strategy. They are already implementing incentives for low-emission alternative energies and vehicles, encouraging active travel (cycling and walking), public transport and bicycle and car-sharing /pooling schemes to reduce congestion and pollution. They need to access available funding at EU level to support their actions of green gamification in transportation.

The EU, being a front runner in this direction, has funded several very successful initiatives in some member states that had positive outcomes. EU already has a series of best practices in funding the use of gamification platforms to boost sustainable mobility and incentivizing commuters towards less carbon intensive choices. These attempts were ranging from raising awareness to motivating users to change their behaviours or engaging them to play a more active role in their environment. An iconic example of this kind is the project "EMPOWER" - a pioneering multinational research project exploring ways to encourage people to reduce their car dependence and enjoy alternative travel options. It was implemented between 01/05/2015 to 30/04/2018 and funded by the Innovation and Networks Executive Agency through the Horizon 2020 programme. It was managed by the University of Leeds (UK) and had a total budget of $€ 4,898,621$. The main goal was to change citizens travel choices in 
different EU cities by rewarding this change that included changing to public transport, using more active modes such as walking and cycling, sharing cars, travelling in off-peak hours and schemes to help people avoid travelling altogether. The central aspect of the project was relying on testing green gamification techniques by using a range of positive incentives including points, discounts, rewards, community support, prizes, cashback and games on smart devices. In the end, the multi annual project produced also a toolkit allowing more cities and organisations to take up the 'EMPOWER concept' that includes an evidence database, business model templates, software tools and advice on evaluation methodology. The toolkit was intended help industry, policy makers, city authorities and employers to understand and successfully implement positive incentives schemes using smart technologies in the context of existing infrastructure, policy and measures. As the main outcome, the EMPOWER project produced an average of $15-50 \%$ reduction in the use of conventionally fuelled vehicles by EMPOWER participants, a 30\% increase in participants' positive evaluation of urban accessibility and $75 \%$ participant satisfaction with the EMPOWER mobility services (European Commission 2018).

An already classic example of rapidly growing area of sustainable urban transit that successfully used technology mediated persuasive tactics and green gamification is "bikeshare" - the transit services where bicycles are shared among riders who do not own them, usually for a small fee. Examples of leading European bike share operators and suppliers are Donkey Republic, Mobike, Moventia, nextbike, PBSC, Ride on, Smoove and Jump by Uber. Their major advantage is that they are an eco-friendly, and low-cost form of public transportation that simultaneously reducing urban traffic congestion, noise, and air pollution. The net savings of bikeshare programs on carbon emissions provoked anticipation and curiosity as more and more 'green trips' were taken. Preliminary findings also suggest that bike-sharing is displacing between 8-16\% of vehicle trips (McKenzie-Mohr 2011, 123) Moreover, another advantage is that digital records of usage behaviors of bikeshares can be used by researchers to analyse and predict city mobility patterns.

Another very good example is the Asian EcoLifeSG, an app that uses gamification as a way of encouraging eco-friendly behaviour. It was developed 
by the Singapore Environment Council (SEC) and it is based on users that can 'level up' their so-called "eco-avatar " through daily challenges in energy, food consumption and waste generation to reduce their carbon footprint. This allows them to monitor their environmental impact, and take progressive steps to go "green". Once an individual creates their user profile, they will be given an "Eco Avatar that will grow as they achieve more carbon reductions. It was part of SEC's digital engagement strategy which uses technology to encourage people to live more environmentally-sustainable lifestyles by applying green gamification techniques, that are believed to be more fun and enjoyable (ind.ecolifesg.com).

Another example is offered in a research by Olszewski et al (2018) that tested a gamified solution to transport problems in a smart city's office district in Warsaw (Poland). In the end they showed that the car polling solution that was developed based on green gamification principles could significantly reduce the number of cars, and, consequently, to alleviate traffic jams, as well as to curb pollution and energy consumption.

Another example of uses of gamification platforms to boost sustainable mobility is the solution found by Public Works Agency, through which the number of workers commuting by car or motorbike decreased from $69 \%$ to $51 \%$ between July 2016 and January 2018. Since the use of gamification platforms in July 2016 till January 2018, up to $45 \%$ of Public Works Agency Staff had join them and participated in the different sustainable mobility challenges carried out in the company and between different companies (interergeurope.eu 2019).

Another successful example is the app named "Own Your Own CO2" that was created in partnership with JouleBug. It combines social media, gamification, and mobile experiences. Users are encouraged to 'buzz' an alert each time they perform a sustainable action which will reduce the size of their carbon footprint, from using a reusable coffee mug to recycling a sheet of paper (oneyoungworld.com 2019).

Another best practice example is in the Bolzano region of South Tirol (Northern Italy), where the regional public transportation company SASA successfully applied a gamed solution in its attempt to educate and motivate its customers to prefer public transportation instead of own vehicles, in order to reduce fossile 
fuels consumption, avoid pollution and protect the natural environment (Globenewswire.com 2019).

Next, the paper draws a series of lessons learnt and proposes a set of characteristics for any project of green gamification for cutting gas emissions in the EU, building on the previous models of best practices. The current proposal includes any green gamification strategy format for promoting more sustainable means of transport (such as public transport, or the use of car-sharing, or bike sharing) that reward players who accomplish desired tasks. Proposed solutions for gamifying EU decarbonisation for 2050 should start from education campaigns to concrete measures taken by the local administrations, incentives to empower and reward people for reducing their carbon footprint: reducing the number of cars, promoting common transportation and encouraging greener alternatives. Measures include shifting car passengers to trains, buses, walking, and cycling; improving road freight logistics and shifting road freight to rail; and getting more people into each car and bus. These gamified solutions need to be based on acknowledging and rewarding customers for their green behaviours and to motivate them to continue doing it, for using strategies to cut carbon emissions especially by convincing people to reduce the use of private cars. For this motivational aspect to be activated rewards need to be earned by all users that take 'green transportation' such as riding the bus or train, walking, biking, or carpooling. It aims to motivate a sustainable behaviour within companies, institutions and citizens, with the use of interactive games, in order to fight against pollution and climate changeThis could be applied into EU-funded projects using game features to support a shift in urban behaviours towards more sustainable and liveable cities. The implementation of the proposed gamified solutions would help to reduce the number of cars by several dozen percent, significantly reduce energy consumption, eliminate traffic jams, and increase the activity of the smart city residents. This tool would be particularly addressed to local administrations in the EU, but also available for businesses and other private or public entities and focused on creative ways that empower and reward individuals' efforts to reduce GHG emissions. This game can be an adaptable educational and learning tool for raising awareness about several issues regarding eco-innovation. 
Through them, citizens should be encouraged to use more sustainable modes of transport through personalised positive incentives made available via a smartphone app. Based on the current trends in the research of gamification we advocate for the development of game-based practices to incentivise citizen's behaviour to achieve new EU transport and mobility policy goals for 2050 following the next caractheristics:

- goal-setting - defining daily tasks for which users earn "points" when completed based on the principle: the more green trips, the more points, the more rewards; the purpose would be to stimulate citizens engaging in socalled 'green transit behaviors' by rewarding "more points" for zero-carbon trips such as bicycling and walking and/or by tracking and encouraging progress from week-to-week;

- tailor-made incentives: to motivate users to achieve the stated goals of reduced $\mathrm{CO} 2$ emissions and help them overcome negative associations they may have the tasks it requires them to complete; The app shall rely on a tailor-made reward mechanism consisting of earning points, obtaining virtual goods, leveling up and completing achievements, the use of leaderboards to display competitive results and celebrate winners;

- colourful, with a fresh design and centered on stimulating playfulness: this will appeal particularly to to younger generations and digital natives by turning to games to learn about $\mathrm{CO} 2$ emissions to their specific context;

- add a social pressure dimension: introduce countdowns and peer-to-peer encouragement for completing 'green' goals'; to this add the possibility for users to share their accomplishment on various social networks;

- centre it on offering constant feed back: the app needs to offer immediate feedback about how currently sensed or predicted user's behaviors affect the environment. This can be achieved through a visual so-called "reward screen" which is reached by each user when taking 'green transit' activities, that are sensed through a combination of self-report and automatic inference, rewarded with this type of messages for example: "Taking the bus to work has saved you 53 carbon points. Traveling by car this could have cost you \$22.56 (incl. gas, insurance, and maintenance costs)" etc. 
- diverse set of benefits, not a one-size-fits-all model: outlining a specific set of benefits for using the app through a representation of eco-friendly transportation along with other goals - saving money, track distances, rewarding bonuses, showing the number of calories burned and highlighting $\mathrm{CO} 2$ emissions saved for each ride.

- present valid up-to-adate information and focus on educational purposes: produce evidence about how user's actions aggregate and impact the environment. Convey complex results in a simple, easy to understand format; make all the available information on local efforts to reduce GHG emissions easily accessible and in a comprehensive and meaningful way. More education and learning about how harmful passenger car gas emissions are to the environment. Visuals are very useful and more persuasive in explaining how small everyday choices can have a visible impact on long term; identifying new innovative ways of presenting environmental impact of our transport choices in a more appealing way.

- stay collaborative: It needs to push collaboration instead of pure competition. In the beginning users will play as individual actors but through a journeylike experience, and during the course of action players' skills will be matched with certain challenges coping successfully with $\mathrm{CO} 2$ reduction and the winners will be encouraged to form teams and apply collaborative decisions to achieve economic and environmental progress.

- revise and reiterate: gamified designs should go through continuous improvement as new research emerges and more data is accumulated (especially in the very complex realities of EU's carbon neutral goal for 2050).

\section{CONCLUSIONS}

Transport generates vast amounts of greenhouse gas emissions and exhaust gases, contributing to climate change and air pollution. All stakeholders in the field of transport agree the undeniable fact that Europe must reduce emissions further and faster. Most visibly, the urgency of swift policy action on decarbonisation of road transport in the EU has increased with the Paris 
Agreement signed in 2015. In order to confirm this urgency, the European Green Deal was launched at the end of 2019 and set new policy goals, seeking a 90\% reduction of greenhouse gas emissions in transport by 2050. To address this challenge, the Green Deal targets not only C02 emissions, but also reducing urban congestion, and tackles the need to improve public transport. As the sustainability concerns become vital for policy planning, the paper advocates for the need of all EU's main stakeholders in the field of transport to realise the potential of this emerging concept and set of practices titled 'green gamification' to help EU member states reach these ambitious policy goals, particularly in the field of transport and mobility - which are of crucial importance for overall CO2 reduction by 2050. The paper offered first an overview of the main policy issues that EU is currently facing in the field of transport and commuting pollution. Then it discussed the rapid evolution of the concept "gamification", trying to shed light on its multiple meanings and achievements in recent years, Next, it addressed the more specific concept of "green gamification" that is, simply put, a form of persuasive game-based technology designed to promote proenvironmental attitudes and behaviors. Applied on the specific field of transport policy the paper outlines the fact that 'green gamification' could provide multiple persuasive tools to engage more citizens in cutting everyday carbon emissions in their lives, because it has already proven efficient in many cases. It is based on the assumption that large scale behavioural change can bring about positive impacts on air quality and carbon emissions given certain circumstances that replicate the successful evolution of gamification, a design that allows players to earn points and virtual trophies and share their achievements with others.

Overall, the analysis aimed to explore various tools available, from the field of eco-innovation, that imply using technology and game mechanics to help achieving Green Deal targets and reduce pollution. In its final remarks the paper drew a set of lessons learnt on the main features a green gamification type of solution should have in order to incentivise citizen's behaviour to achieve new EU transport and mobility policy goals for 2050. The paper also illustrated with a set of examples how green gamification principles have produced expected results. With the help of internet and wide access to smart phones, games prove 
to be interactive, but also educative, efficient and proactive systems of persuading citizens to make pro-environmental choices. The visible, quantifiable impact of these measures is reflected in the increase the use of more sustainable modes of transport like public transport and bicycles, together with the boom of car sharing and bikes hating programmes in all EU major cities.

Analysing the areas in which gamification has the potential to improve transport sustainability in the context of the EU's new policy goals set by the 'Green Deal', the main hypothesis of the article was validated, showing by why and how gamification may contribute to the ambitious plan of decarbonizing the continent within the next three decades. In the last section the paper argued that it is very relevant at this point to understand the potential and the pitfalls of 'green gamification' in order to leverage digital technologies \& innovations to enhance the uses of available EU funding for financing for sustainable development and decarbonisation.

Overall, climate change in general, and pollution in particular are very complex phenomena, producing multi-faceted problems. The current situation we find ourselves into, rises an important question: can gamification play a serious role in proposing feasible environmental solutions? The paper presented several best practices cases of successful 'green gamification' with a potential to be extended at a larger scale. Next, it discussed its own set of recommendations but it also showed possible critical points and limitations of these tools. One such possible limitation was that many new emerging business models developed around green gamification just for the sake of being 'trendy' or up to date with new evolutions, but not looking for real sustainable impact on the environment. Another limitation of their application was that it is very challenging to gather data in order to evaluate how reduced levels of air pollution and a positive change in air quality directly correlates with the uses of 'green gamification' to promote solutions like bike-sharing or other similar eco-friendly products that cut CO2 harmful emissions. So, indeed, we can argue that not by simply using elements of green gamification to promote a change in citizens' everyday choices (like choosing public transport instead of personal car to go to work) is sufficient for a visible sustainable decrease in $\mathrm{CO} 2$ emissions. An important conclusion is that green gamification should be seen as rather a factor facilitating 
change for more pro-environmental choices among many other factors, such as national policies, local implementation and coordinated actions and regulations at EU level. A lot depends on how gamification is designed, but also how it is used in order to have the expected impact. In the end, we need to stress that games can not solve problems on their own. Instead, we need to understand that games might be a good way of conceptualizing and understanding problems, and facilitate engagement, rather than offering ready made solutions.

Another very relevant idea that resulted from the study is that the EU's generous funding attached to the Green Deal ambitious objective, even during the economic challenges of the COVID pandemic, can not sustain only by itself. The fight against climate change requires the combined efforts of a complex web of diverse actors: EU institutions and financial stimulus, all EU member states' institutions, companies, NGOs and citizens. A lot of attention is put on the regional and local level, where grass root initiatives are expected to bring the most visible results, besides the Council decisions and national law enforcement agents. But in environmental topics, such as reducing $\mathrm{CO} 2$ emissions, like in many other crucial fields for the EU, not all regions start on an equal footing. Very wide economic discrepancies among regions in the EU (sometimes even among the regions in the same country) show also that there are wide discrepancies in terms of transposing EU laws or developing instruments to fight heavy air pollution. Many of these topics need to be further discussed in future research.

\section{REFERENCES}

- Burke, Brian. 2014. Gamify: How gamification motivates people to do extraordinary things. Brookline, MA: Gartner, Inc.

- Bui, An and Daniel Veit. 2015. "The Effects of Gamification on Driver Behavior: An Example from a Free Float Carsharing Service", ECIS 2015 Research-in-Progress Papers. Paper 28. Accessed 22.08.2020 https://aisel.aisnet.org/ecis2015_rip/28. 
- Deterding, Sebastian, Dan Dixon, Rilla Khaled and Lennart Nacke. 2011. "From game design elements to gamefulness: defining "gamification"" in Proceedings of the 15th International Academic MindTrek Conference: Envisioning Future Media Environments (MindTrek '11). New York, USA: ACM.

- Domínguez, Adrian. Saenz-de-Navarrete, Joseba. De-Marcos, Luis. Fernández-Sanz, Luis. Pagés, Carmen and Martínez-Herráiz, Jose-Javier. 2013. "Gamifying learning experiences: Practical implications and outcomes". Computers \& Education. 63:380-392.

- European Commission. 2011. "White Paper 2011, Roadmap to a Single European Transport Area - Towards a competitive and resource efficient transport system". Accessed 22.08.2020, https://ec.europa.eu/transport/themes/strategies/2011_white_paper_en.

- European Commission, "Transport emissions, A European Strategy for low-emission mobility". 22.08.2020. https://ec.europa.eu/clima/policies/transport_en.

- European Commission. 2017. "Delivering on the European Strategy for low-emission mobility". 22.04.2020. https:/ /ec.europa.eu/transport/sites/transport/files/2017-11-08-mobilitypackage two/factsheet_encouraging_clean_mob.pdf.

- European Commission. "Mobility and transport." Accessed 22.08.2020. https:/ / ec.europa.eu/transport/modes/road/road-initiatives_en.

- European Commission. 2016. Directive (EU) 2016/2284. Accessed 22.08.2020, https:/ / eur-lex.europa.eu/legalcontent/EN/TXT/?qid=1593765728744\&uri=CELEX:52020DC0266.

- European Commission. 2019. "The European Commission's priorities". Accessed 22.08.2020. https://ec.europa.eu/info/strategy/priorities-20192024.

- European Commission. 2019. COM/2019/640. Accessed 22.08.2020. https://eur-lex.europa.eu/legalcontent $/$ EN/TXT/?qid=1576150542719\&uri=COM\%3A2019\%3A640\%3AFI N. 
- European Commission. 2019. "Transport in the European Union - Current trends and issues". 22.08.2020. https:/ / ec.europa.eu/transport/sites/transport/files/2019-transport-inthe-eu-current-trends-and-issues.pdf.

- European Commission. 2019. "A European Green Deal". Accessed 22.08.2020. https://ec.europa.eu/info/strategy/priorities-20192024/european-green-deal_en and https:/ / ec.europa.eu/transport/modes/road/roadinitiatives/decarbonisation_en.

- European Commission. 2020. "Innovation and Networks, Empowering a reduction in use of conventionally fueled vehicles using Positive Policy Measures". Accessed 22.08.2020. https://ec.europa.eu/inea/en/horizon2020/projects/h2020-transport/urban-mobility/empower.

- European Commission. 2020. “Commission welcomes ambitious agreement on key legislation to cut down greenhouse gas emissions". Accessed 22.08.2020. https://ec.europa.eu/clima/news/commission-welcomesambitious-agreement-key-legislation-cut-down-greenhouse-gasemissions_en.

- European Investment Bank Group. 2020. “Transport OVERVIEW 2020". Accessed 22.08.2020. https://www.eib.org/attachments/thematic/transport_overview_2020_en .pdf.

- European Environment Agency. 2020. "National Emission reduction Commitments Directive reporting status 2020". Accessed 22.08.2020. https://www.eea.europa.eu/themes/air/air-pollution-sources-1/nationalemission-ceilings/national-emission-reduction-commitments-directive.

- European Environment Agency. 2019a. "Average CO2 emissions from new cars and new vans increased again in 2019". Accessed 22.08.2020. https://www.eea.europa.eu/highlights/average-co2-emissions-from-newcars-vans-2019.

- European Environmental Agency. 2019b. "Greenhouse gas emissions from transport in transport in Europe". Accessed 22.08.2020. https://www.eea.europa.eu/data-and-maps/indicators/transport- 
emissions-of-greenhouse-gases/transport-emissions-of-greenhouse-gases12.

- European Environmental Agency. 2018. "Progress of EU transport sector towards its environment and climate objectives". Accessed 22.08.2020. https://www.eea.europa.eu/themes/transport/term/term-briefing-2018.

- Filimon-Lecka, Olga. 2020. "Can we forget about gamification once and for all?". UX Collective. Accessed 22.08.2020. https://uxdesign.cc/can-weforget-about-gamification-once-and-for-all-dac819db46a.

- Fitz Walter, Zachary, "What is Gamification?". Gamify. Accessed 22.08.2020. https://www.gamify.com/what-is-gamification.

- Froehlich. Jon .2015. "Gamifying Green: Gamification and Environmental Sustainability". In Walz, S. and Deterding, S. (Eds.), The Gameful World, MIT Press. Accessed 22.08.2020. https://makeabilitylab.cs.washington.edu/media/publications/Gamifyin g_Green_Gamification_and_Environmental_Sustainability_yy7Jx99.pdf.

- GlobeNewswire. 2019. "Bombardier, Autonomous Province of BolzanoBozen and STA celebrate launch of the sustainable mobility plan for Italy's region of South Tyrol". Accessed 22.08.2020. https://www.globenewswire.com/newsrelease/2019/09/11/1914350/0/en/Bombardier-Autonomous-Province-ofBolzano-Bozen-and-STA-celebrate-launch-of-the-sustainable-mobility-planfor-Italy-s-region-of-South-Tyrol.html.

- Huotari, Kai and Hamari, Juho. 2012. "Defining gamification: A service marketing perspective". In Proceedings of the 16th international academic MindTrek conference. New York, NY: Academic MindTrek Conference, 1722.

- Interreg Europe. 2019. "Use of gamification platforms to boost sustainable mobility". Accessed 22.08.2020. https://www.interregeurope.eu/policylearning/goodpractices/item/2219/use-of-gamification-platforms-to-boost-sustainablemobility/. 
- Kapp, Karl. M. 2012. The gamification of learning and instruction: Game-based methods and strategies for training and education. San Francisco, CA: John Wiley.

- Landers, Richard. N. 2019. “Gamification Misunderstood: How Badly Executed and Rhetorical Gamification Obscures Its Transformative Potential". Journal of Management Inquiry, 28(2): 137-140.

- Landers, Richard N. Auer, Elena M. Collmus, Andrew Burnett. Armstrong, Michael B. 2018. "Gamification science, its history and future: Definitions and a research agenda". Simulation $\mathcal{E}$ Gaming, 49: 315-337.

- Lounis, Stavros, Xanthippi Neratzouli and Pramatari Katerina. 2013. "Can Gamification Increase Consumer Engagement? A Qualitative Approach on a Green Case". In: Douligeris C., Polemi N., Karantjias A., Lamersdorf W. (eds) Collaborative, Trusted and Privacy-Aware e/m-Services. I3E 2013. IFIP Advances in Information and Communication Technology, vol 399. Berlin, Heidelberg: Springer.

- Makower, Joel. 2012. State of Green Bussiness Report. Accessed 22.08.2020. https://www.oneplanetnetwork.org/sites/default/files/state_of_green_b usiness_2012.pdf.

- Mazur-Stommen, Susan \& Kate Farley. 2016. "Games for Grownups: The Role of Gamification in Climate Change and Sustainability". Indicia $\begin{array}{lll}\text { Consulting } \quad \text { LLC. } & \text { 22.08.2020. }\end{array}$ http:/ / indiciaconsulting.com/downloads/Games-for-Grownups-ClimateChange-Edition.pdf.

- McKenzie-Mohr, Doug. 2009. Fostering Sustainable Behavior. McKenzie-Mohr \& Associates, Inc.

- Olszewski, Robert, Piotr Pałka and Agnieszka Turek. 2019. "Solving "Smart City" Transport Problems by Designing Carpooling Gamification Schemes with Multi-Agent Systems: The Case of the So-Called "Mordor of Warsaw". Sensors (Basel, Switzerland). 2018 Jan. 18(1).

- $\quad$ oneyoungworld.com. 2019. “Using gamification to deter over 23,000 kgs of CO2". Accessed 22.08.2020. https://www.oneyoungworld.com/newsitem/ using-gamification-deter-over-23000-kgs-co2. 
- The GreenBiz Group. 2012. "State of Green Business Report". Accessed 22.08.2020. https://www.greenbiz.com/report/state-green-businessreport-2012.

- UN. 2020. “Climate Change". Accessed 22.08.2020. https://www.un.org/en/sections/issues-depth/climate-change/.

- UNEP (United Nations Environmental Programme), 2020. "Facts about climate emergency". Accessed 22.08.2020. https://www.unenvironment.org/explore-topics/climate-change/factsabout-climate-emergency.

- Urban NO2 Atlas. 2019. Accessed 22.08.2020. https://ec.europa.eu/jrc/en/publication/eur-scientific-and-technicalresearch-reports/urban-no2-atlas.

- Vălean, Adina. 2020. "EU strategy for mobility and transport: measures needed by 2030 and beyond". Accessed 22.08.2020. https:/ / ec.europa.eu/transport/themes/strategies/news/2020-02-03commissioner-valeans-speech-eu-strategy-mobility-and-transport_en.

- Walz, Steffen. P. and Sebastian Deterding (Eds.). 2015. The Gameful world. Cambridge, MA: The MIT Press.

- Werbach, Kevin. 2014. "(Re)Defining Gamification: A Process Approach". In: Spagnolli A., Chittaro L., Gamberini L. (eds) Persuasive Technology. PERSUASIVE 2014. Lecture Notes in Computer Science, vol 8462. Springer, Cham. https://doi.org/10.1007/978-3-319-07127-5_23.

- WHO. 2019. "Ambient air pollution: A global assessment of exposure and burden of disease". https://www.who.int/phe/health_topics/outdoorair/databases/en/ .

- WHO. 2018. "Ambient air quality and health". Accessed 22.08.2020. https://www.who.int/news-room/fact-sheets/detail/ambient-(outdoor)air-quality-and-health.

- Wolf, Tobias. 2020. "Green gamification: How gamified information presentation affects pro-environmental behavior". Proceedings of the GamiFIN Conference 2020, Levi, Finland, April 1-3, 2020 (organized online). 8291. http://ceur-ws.org/Vol-2637/paper9.pdf 
- Yuan Hung, Aaron Chia. 2017. "A Critique and Defense of Gamification" Journal of Interactive Online Learning, Vol. 15 (1) Summer 2017. Accessed 22.08.2020. https://www.ncolr.org/jiol/issues/pdf/15.1.4.pdf.

- Zhanga, Kai and Stuart Battermanb. 2013. "Air pollution and health risks due to vehicle traffic". Sci Total Environ. 2013 April 15. 0: 307-316. doi:10.1016/j.scitotenv.2013.01.074.

- Zichermann, Gabe and Christopher Cunningham. 2011. Gamification by design. Sebastopol, CA: O’Reilly Media. 